\title{
Chloride Diffusivity and Life Prediction of Cracked RC Beams Exposed to Different Wet-Dry Ratios and Exposure Duration
}

\author{
Jieqiong Wu, ${ }^{1}$ Bo Diao, ${ }^{1,2}$ Yinghua Ye, ${ }^{1}$ and Xiaoning Zheng ${ }^{1,2}$ \\ ${ }^{1}$ School of Transportation Science and Engineering, Beihang University, Beijing 100083, China \\ ${ }^{2}$ State Laboratory of Subtropical Building Science, South China University of Technology, Guangzhou 510640, China \\ Correspondence should be addressed to Bo Diao; diaobo@buaa.edu.cn
}

Received 6 February 2017; Revised 31 March 2017; Accepted 4 May 2017; Published 11 June 2017

Academic Editor: Francesco Caputo

Copyright (c) 2017 Jieqiong Wu et al. This is an open access article distributed under the Creative Commons Attribution License, which permits unrestricted use, distribution, and reproduction in any medium, provided the original work is properly cited.

\begin{abstract}
Effects of crack width, wet-dry ratio, and exposure duration of wet-dry cycles on chloride ingress of RC beams were experimentally studied. Crack widths of 40, 70, 90, and 120 microns were, respectively, induced by three-point flexural loading and four wet-dry ratios (seawater spraying $1 \mathrm{~d}$ in one wet-dry cycle) of $1: 3,1: 7,1: 11$, and $1: 15$ were selected. Chloride contents of RC beams were tested every $32 \mathrm{~d}$ (or $16 \mathrm{~d}$ ) of wet-dry cycles. Results show that chloride content increased significantly when crack width was larger than 90 microns and wet-dry ratio was $1: 3$, and it increased slightly when crack width was 120 microns and wet-dry ratio was $1: 7,1: 11$, and $1: 15$. The chloride content on steel bar surface became the largest when crack width was less than 90 microns and wet-dry ratio was $1: 7$, and while crack width was equal to or greater than 90 microns and wet-dry ratio was $1: 3$, it was the largest. Based on the testing results, chloride diffusion model and prediction model of residual service life of RC beams were suggested considering combined effects of crack width and exposure duration. The predicted residual service lives were corresponding well with experimental results and they decreased as crack width increased.
\end{abstract}

\section{Introduction}

The attack of chloride corrosion is one of the major factors that reduce durability of existing reinforced concrete (RC) structures in coastal region; these structures are normally worked with cracks induced by service loading. The corrosive medium (e.g., chloride, oxygen, and water) could penetrate into concrete through these cracks. So RC structures in coastal region normally suffered the combined action of cracks and chloride corrosion [1]. There are many experiments about chloride ingress of concrete structures exposed to the environment of seawater wet-dry cycles, but few experiments investigated the difference of chloride diffusion when RC structures are exposed to chloride environments with different ratios of wetting time and drying time.

Hong and Hooton [2] immersed plain concrete specimens in $1.0 \mathrm{~mol} / \mathrm{L} \mathrm{NaCl}$ solution for $6 \mathrm{~h}$, and then these specimens were dried for $18 \mathrm{~h}$ (one-day cycle) or $66 \mathrm{~h}$ (threeday cycle). After $1,4,9,16,25$, and 36 cycles (one-day cycle) and $1,4,9,16$, and 25 cycles (three-day cycle), the testing results of chloride content showed that prolonging the drying time could increase the rate of chloride ingress and there existed a good relationship between the depth of chloride penetration and the square root of the number of cycles. C. $\mathrm{Li}$ and $\mathrm{K}$. Li [3] experimentally studied the law of chloride diffusion in the process of wet-dry cycles. The exposed surface of specimens contacted $1.0 \mathrm{~mol} / \mathrm{L} \mathrm{NaCl}$ solution for $12 \mathrm{~h}$ and then dried at $20^{\circ} \mathrm{C}, \mathrm{RH} 70 \%$. Wet-dry ratios were $1: 6$; $1: 13 ; 1: 27$, respectively. It was indicated that when wet-dry ratio was $1: 6$ and $1: 13$, the content of acid-soluble chloride ion was relatively larger. Gang et al. [4] immersed specimens in $7 \%$ (by weight) $\mathrm{NaCl}$ solution, and wet-dry ratios were $1: 1,3: 1,5: 1,1: 3$, and $1: 5$, respectively, and cycling time was $48 \mathrm{~h}$. The testing results of chloride content showed that, with the decrease of wet-dry ratio, the peak concentration of convection became higher. These indicated that chloride diffusion in uncracked concrete was significantly influenced by wet-dry ratios. But few experiments investigated the effect of wet-dry ratios on chloride diffusion of cracked RC structures. 
$\mid 1$

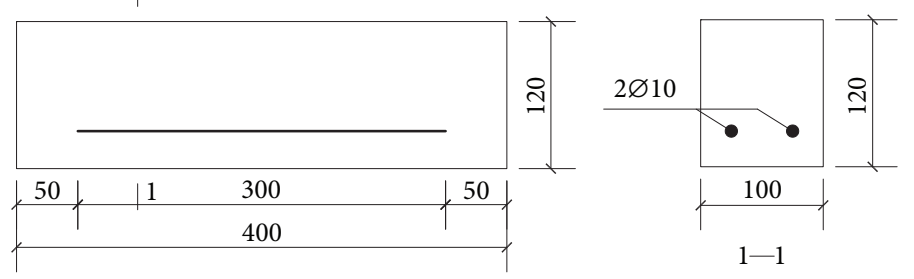

FIGURE 1: Dimensions and reinforcements of RC beams.

Apparent chloride diffusion is time-dependent, and it decays with time for the reason that pore structure is being more compact as the continuous hydration of concrete and the repulsive effect of anions on chloride ion [5]. Mangat and Molloy [6] placed concrete specimens in the tidal zone at Aberdeen beach for up to 3.3 years and tested the chloride content of concrete. The testing results showed that as the exposure duration increased, the chloride content increased but the increasing rate reduced; that is, chloride diffusion coefficient reduced. Moradllo et al. [7] measured the surface chloride content of concrete with different surface coatings in tidal zone during five years. It was found that surface chloride content of most specimens increased and chloride diffusion coefficient decreased as exposure duration increased.

Şahmaran [8] studied the effect of cracks, where specimens were immersed in $\mathrm{NaCl}$ solution for $30 \mathrm{~d}$ at concrete age of $43 \mathrm{~d}$. Results showed that when crack width was less than 135 microns, the effect of cracks on chloride diffusion coefficient could be neglected; and when crack width was larger than 135 microns, the diffusion coefficient increased obviously. Win et al. [9] applied a bending load to induce four widths of cracks $(100,200,300$, and 500 microns) in concrete specimens. Then the specimens were immersed in $\mathrm{NaCl}$ solution for 1 month. The results of Electron Probe Microanalysis showed that the chloride penetration profile around the crack was more than twice that in the uncracked surface. Lei et al. [10] tested the chloride content of RC columns after 100 wet-dry cycles and calculated chloride diffusion coefficients. Immersing for $8 \mathrm{~h}$ and naturally drying for $16 \mathrm{~h}$ acted as one wet-dry cycle. Results showed that when crack width was less than 100 microns, chloride content and diffusion coefficient changed little. When 100 microns $\leq$ width $\leq 140$ microns, the chloride content on steel bar surface increased slightly while diffusion coefficient increased significantly. $\mathrm{Li}$ [11] sprayed $\mathrm{NaCl}$ solution to specimens for $8 \mathrm{~h}$, and then these specimens were naturally dried at $25^{\circ} \mathrm{C}$ and $\mathrm{RH} 60 \%$ for $1 \mathrm{~d}$ and then dried at $50^{\circ} \mathrm{C}$ and $\mathrm{RH} 20 \%$ for $1 \mathrm{~d}$. After the designed wet-dry cycles, chloride contents of concrete with three widths of cracks (less than 50 microns, 100 microns, and 200 microns) were tested. It was shown that when crack width was greater than 100 microns, cracks had significant effect on chloride content of concrete. Existing experiments mainly considered the effect of single factor such as crack width, or wet-dry ratio, or exposure duration on chlorine ion permeability, but few considered the combined effects of crack width, wet-dry ratio, and exposure duration.
TABLE 1: Concrete mixture composition $\left(\mathrm{kg} / \mathrm{m}^{3}\right)$.

\begin{tabular}{lc}
\hline 425 Portland cement & 315 \\
Water & 170 \\
River sand & 661 \\
Coarse aggregates & 1284 \\
\hline
\end{tabular}

Note. 425 Portland cement refers to a cement class in China; its compressive strength at age of $28 \mathrm{~d}$ was $42.5 \mathrm{MPa}$.

The working conditions of RC structures in coastal region were stimulated in lab and the evolution of crack widths, chloride diffusivity, and service life were experimentally investigated considering different wet-dry ratios $(1: 3,1: 7$, $1: 11$, and $1: 15$ ), different crack widths (0 120 microns), and different exposure durations ( $32 \mathrm{~d} \sim 160 \mathrm{~d})$. Based on the research, the model of chloride diffusion and life prediction of RC beams, where the combined effects of crack width and exposure duration were considered, were proposed.

\section{Specimen and Testing Program}

2.1. Specimens. The working conditions of RC structures in coastal region were stimulated in lab and the combined effects of crack width, wet-dry ratio, and exposure duration on evolution of crack widths, chloride diffusivity, and service life were experimentally investigated. The testing environments in the current study included seawater wet-dry environment and laboratory natural environment. Total 150 RC beam specimens with same sizes and same reinforcements were made, where 102 beam specimens were exposed in the environment of seawater wet-dry cycles, and 21 beams were placed in lab atmosphere environment as reference group. The rest of 27 beam specimens were used as to study how to induce the designed width of cracks and acted as spare specimens in the wet-dry cycles.

The reinforcement arrangements of $\mathrm{RC}$ beam specimens are showed in Figure 1. The dimension of the rectangular cross-section was $100 \mathrm{~mm} \times 120 \mathrm{~mm}$, and the length of the beam specimen was $400 \mathrm{~mm}$. The diameter of longitudinal tensile steel bar was $10 \mathrm{~mm}$ and concrete cover was $30 \mathrm{~mm}$. The mixtures of concrete included 425 Portland cement, river sand, and coarse aggregates. The maximum size of aggregate was $10 \mathrm{~mm}$ and the water-cement ratio was 0.54 . The concrete mixture composition in per cubic meter is given in Table 1. The average compressive strength of the concrete used for the 
TABLE 2: Names of RC beam specimens (Group $A=1: 3$, or $B=1: 7$, or $D=1: 15$ ).

\begin{tabular}{|c|c|c|c|c|c|c|c|}
\hline \multirow{2}{*}{ Crack width } & \multicolumn{7}{|c|}{ Duration } \\
\hline & $32 \mathrm{~d}$ & $48 \mathrm{~d}$ & $64 \mathrm{~d}$ & $96 \mathrm{~d}$ & $128 \mathrm{~d}$ & $144 \mathrm{~d}$ & $160 \mathrm{~d}$ \\
\hline 00 microns & A- $00-32$ & A- $00-48$ & A-00-64 & A-00-96 & A-00-128 & A-00-144 & A- $00-160$ \\
\hline 40 microns & A- $40-32$ & A- $40-48$ & A-40-64 & A-40-96 & A- $40-128$ & A- $40-144$ & A- $40-160$ \\
\hline 70 microns & A-70-32 & - & A-70-64 & A-70-96 & A-70-128 & - & A-70-160 \\
\hline 90 microns & A-90-32 & - & A-90-64 & A-90-96 & A-90-128 & - & A-90-160 \\
\hline 120 microns & A-120-32 & - & A-120-64 & A-120-96 & A-120-128 & - & A-120-160 \\
\hline
\end{tabular}

TABle 3: Names of RC beam specimens (Group C $=1: 11$ ).

\begin{tabular}{lcccccc}
\hline Crack width & & & \multicolumn{2}{c}{ Duration } \\
& $32 \mathrm{~d}$ & $48 \mathrm{~d}$ & $64 \mathrm{~d}$ & $96 \mathrm{~d}$ & $128 \mathrm{~d}$ & $144 \mathrm{~d}$ \\
\hline 00 microns & - & C-00-48 & - & C-00-96 & - & C-00-144 \\
40 microns & - & C-40-48 & - & C-40-96 & - & C-40-144 \\
70 microns & - & C-70-48 & - & C-70-96 & - & C-70-144 \\
90 microns & - & C-90-48 & - & C-90-96 & - & C-90-144 \\
120 microns & - & C-120-48 & - & C-120-96 & - & C-120-144 \\
\hline
\end{tabular}

$150 \mathrm{RC}$ beam specimens was $41 \mathrm{MPa}$, as determined on the prisms at an age of 28 days.

2.2. Testing Program. All tests were performed in the Civil Engineering Laboratory at Beihang University in Beijing. Based on the wet-dry ratios, 102 beam specimens were classified into A, B, C, and D four groups, and the wet-dry ratio is as follows: Group $A=1: 3$, Group $B=1: 7$, Group $\mathrm{C}=1: 11$, and Group $\mathrm{D}=1: 15$, which means that the beam specimens were subjected to seawater spraying for $1 \mathrm{~d}$ and then atmosphere drying in lab environment for $3,7,11$, and $15 \mathrm{~d}$, respectively. Within each group, the beam specimens were further divided by five crack widths $(0,40,70,90$, and 120 microns) and seven exposure durations (32 d, $48 \mathrm{~d}, 64 \mathrm{~d}$, $96 \mathrm{~d}, 128 \mathrm{~d}, 144 \mathrm{~d}$, and $160 \mathrm{~d})$. The beam specimens of Groups A, B, and D are summarized in Table 2, named as group number-crack width-exposure duration; for example, A-0032 means Group A, crack width of 00 microns, and exposure duration $32 \mathrm{~d}$, and so on. And beam specimens of Group C are summarized in Table 3.

All beam specimens were demolded after $24 \mathrm{~h}$ of casting and were cured under standard temperature and moisture conditions. At the age of $28 \mathrm{~d}$, three-point flexural loading was performed on RC beam specimens to induce different widths of flexural cracks, where loading increment was controlled by mid-span deflection. The loading equipment was shown in Figure 2. The maximum crack width was measured and recorded with a crack detector after two hours of the beam specimens unloading and classified into five crack widths $(0$, 40, 70, 90, and 120 microns), as listed in Tables 2 and 3.

To simulate the combined actions of crack width, wet-dry ratio, and exposure duration, the beam specimens of Group $A, B, C$, and D were sprayed with seawater for $1 \mathrm{~d}$ and then atmosphere dried in lab environment for $3 \mathrm{~d}$ (Group A), $7 \mathrm{~d}$ (Group B), $11 \mathrm{~d}$ (Group C), and $15 \mathrm{~d}$ (Group D), respectively,

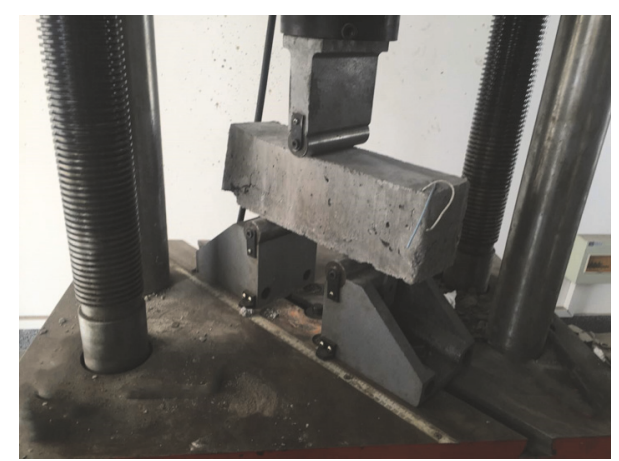

FIGURE 2: Loading equipment.

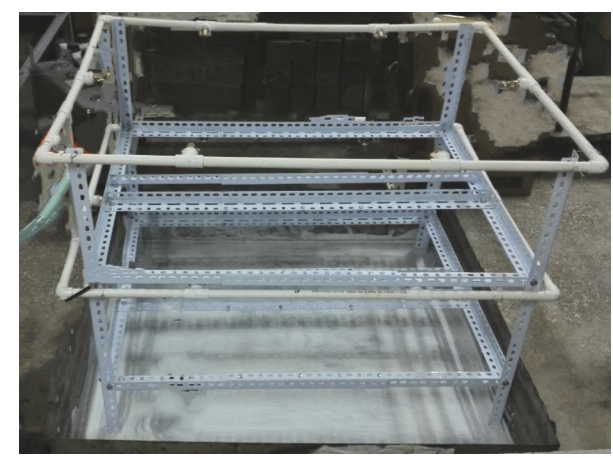

FIGURE 3: Spraying device.

as one round of wet-dry cycle. This procedure was repeated until the designed exposure duration as listed in Tables 2 and 3.

Automatic device of seawater spraying was shown in Figure 3; the seawater here was artificially made with 3.5\% (by 


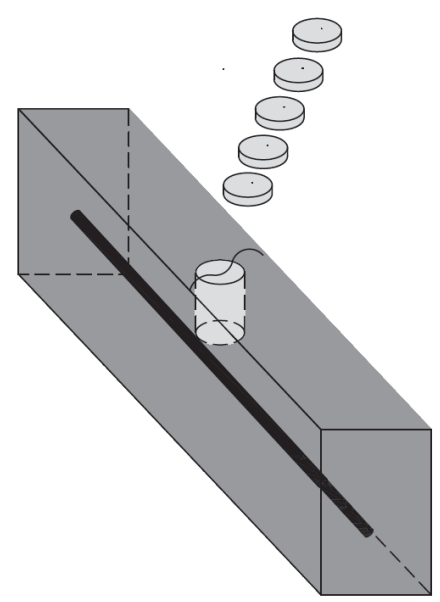

FIGURE 4: Sampling from tensile side of RC beam specimens.

weight) $\mathrm{NaCl}$. In order to ensure one-dimensional diffusion in the process of wet-dry cycles, all beam specimens were coated with waterproof paint except for the testing surface.

After accomplishment of designed exposure duration of wet-dry cycles, a cylinder concrete sample was drilled at tensile side of RC beam specimens, as shown in Figure 4. The diameter and depth of the cylinder sample was $50 \mathrm{~mm}$ and $30 \mathrm{~mm}$, respectively. The cylinder sample was then subdivided into 5 slices along the depth. Each slice was ground into fine powder and the free chloride content in each slice was tested by the Ion Selective Electrode Method [12] according to the standard JTJ 270-98 [13].

\section{Results and Discussion}

The initial cracks on $\mathrm{RC}$ beam specimens were induced by three-point flexural loading at the age of $28 \mathrm{~d}$, and then the load was removed. The beam specimens with different crack widths were exposed to the designed wet-dry ratios and cycles. During the period of wet-dry cycles, the evolution of crack width was monitored. After the designed duration of wet-dry cycles completed, the chloride contents of cracked and uncracked concrete at depths of $0 \sim 6 \mathrm{~mm}, 6 \sim 12 \mathrm{~mm}, 12 \sim$ $18 \mathrm{~mm}, 18 \sim 24 \mathrm{~mm}$, and $24 \sim 30 \mathrm{~mm}$ were tested. The experimental results of crack width and chloride content are briefly introduced as the following.

3.1. Self-Healing Effect of Concrete Cracks. The crack photos of initial widths 120 microns on beam specimens in Groups A, B, C, and D, before $(t=0)$ and after wet-dry cycles, were shown in Figure 5. It can be seen from Figure 5, when initial width was 120 microns after designed wet-dry cycles, selfhealing effect of cracks in Group A (wet-dry ratio 1:3) was quite obvious, and Group B (wet-dry ratio 1:7) was next, and Groups C and D (wet-dry ratios 1:11 and 1:15) were not obvious. Therefore, as wet-dry ratio decreased from $1: 3$ to $1: 15$, self-healing effect of concrete cracks weakened.

Figure 6 shows the photos of cracks on RC beam specimens in Group B, with different initial crack widths of 40, 70, 90, and 120 microns, before $(t=0)$ and after
TABLE 4: Crack width of four groups $(\mathrm{A}=1: 3, \mathrm{~B}=1: 7, \mathrm{C}=1: 11$, and $\mathrm{D}=1: 15)$ after wet-dry cycles.

\begin{tabular}{lcccc}
\hline $\begin{array}{l}\text { Initial width } \\
(t=0)\end{array}$ & Group A & Group B & Group C (144 d) & Group D \\
\hline 40 microns & 00 & 00 & 00 & 00 \\
70 microns & 00 & 30 & 45 & 50 \\
90 microns & 00 & 70 & 75 & 75 \\
120 microns & 40 & 70 & 90 & 90 \\
\hline
\end{tabular}

TABLE 5: Cracks evolution of Group B (1:7) after designed exposure duration.

\begin{tabular}{lccccc}
\hline Initial width & \multicolumn{5}{c}{ Duration } \\
& $32 \mathrm{~d}$ & $64 \mathrm{~d}$ & $96 \mathrm{~d}$ & $128 \mathrm{~d}$ & $160 \mathrm{~d}$ \\
\hline 40 microns & 40 & 35 & 25 & 5 & 00 \\
70 microns & 70 & 65 & 60 & 40 & 30 \\
90 microns & 90 & 90 & 85 & 70 & 70 \\
120 microns & 120 & 120 & 100 & 80 & 70 \\
\hline
\end{tabular}

$(t=160 \mathrm{~d})$ wet-dry cycles. After $160 \mathrm{~d}$ of wet-dry cycles, as shown in Figure 6, when initial crack width was 40 or 70 microns, the crack nearly disappeared due to self-healing effect of concrete materials, while when initial crack width was 90 or 120 microns, self-healing effect was not quite obvious. The conclusion was that as the width of initial cracks increased from 40 microns to 120 microns, self-healing effect of concrete cracks gradually weakened.

The testing results of crack widths after designed wet-dry cycles for four groups are listed in Table 4. It was indicated that self-healing effect of crack surface was the best where the wet-dry ratio was 1:3 (Group A). And when initial crack width was 40 microns, the crack in concrete surface of four groups disappeared after the designed wet-dry cycles. Besides, as the wet-dry ratio decreased from $1: 3$ to $1: 15$ and crack widths increased from 40 microns to 120 microns, selfhealing effect gradually weakened.

The testing results of crack widths in Group B with different initial crack widths and exposure durations were listed in Table 5. It can be seen from Table 5 that as the exposure duration increased from $0 \mathrm{~d}$ to $160 \mathrm{~d}$, the self-healing effects of concrete cracks were observed to be gradually obvious, and as the width of initial crack increased from 40 microns to 120 microns, the self-healing effects of concrete cracks were monitored to be gradually weaken.

In the exposure duration of wet-dry cycles, the selfhealing effect of concrete cracks mainly comes from two aspects. On one hand, the white deposit $\left(\mathrm{CaCO}_{3}\right)$ blocked the crack $[14,15]$, which was chemically formed by $\mathrm{CO}_{2}$ from the air and the alkaline component from concrete. On the other hand, the beam specimens in Group A suffered the longest duration of seawater spraying, which result in sufficient hydration of concrete and obvious self-healing of concrete cracks after $160 \mathrm{~d}$ wet-dry cycles.

3.2. Testing Results of Chloride Content and Discussion. When the designed duration of wet-dry cycles was finished, cylinder 


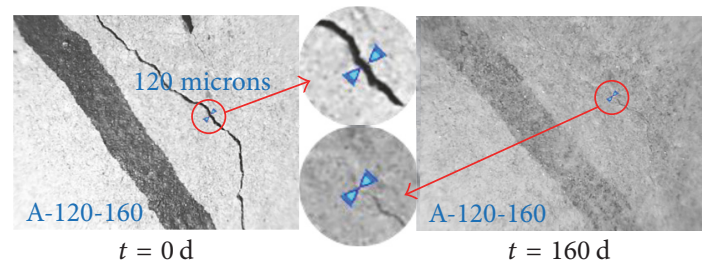

(a)

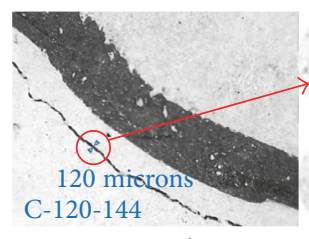

$t=0 \mathrm{~d}$

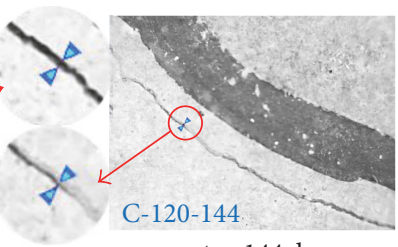

$t=144 \mathrm{~d}$

(c)

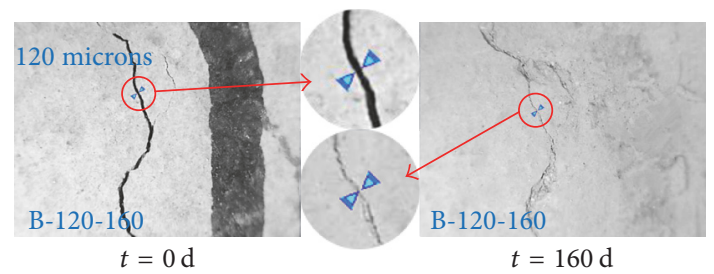

(b)

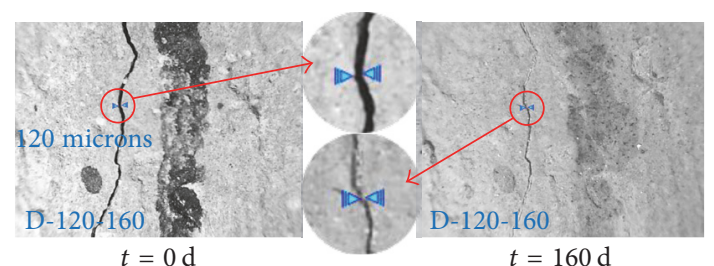

(d)

Figure 5: Cracks in Groups A, B, C, and D (initial width 120 microns) before and after wet-dry cycles: (a) Group A; (b) Group B; (c) Group C; (d) Group D.

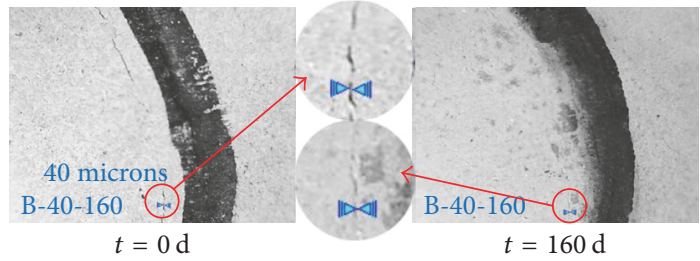

(a)

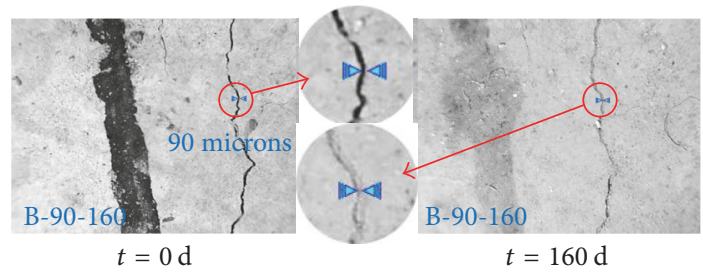

(c)

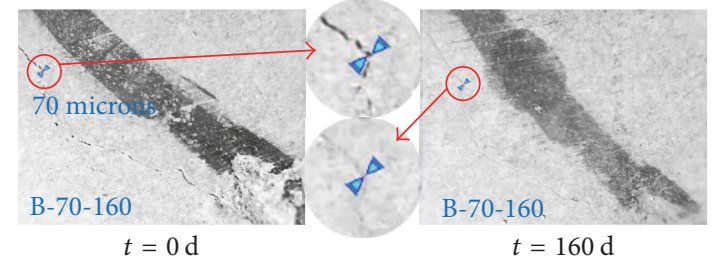

(b)
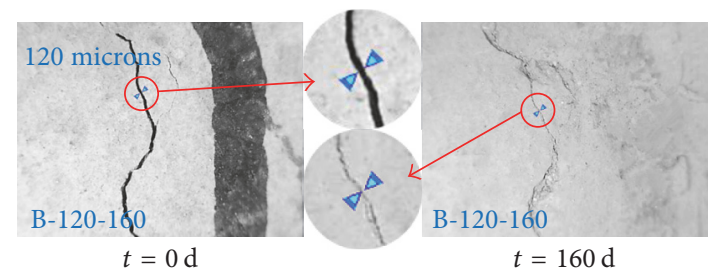

(d)

Figure 6: Self-healing of cracks in Group B (initial width = 40, 70, 90, and 120 microns) before and after wet-dry cycles: (a) 40 microns; (b) 70 microns; (c) 90 microns; (d) 120 microns.

samples were drilled at tensile side of RC beam specimens, as shown in Figure 4. The chloride contents along the depth of concrete cover with different crack widths in four groups were tested. The relationship of the chloride content with the crack width, wet-dry ratio, and exposure duration will be discussed in the following sections.

3.2.1. Effect of Crack Widths on Chloride Content. The chloride contents along the depth of the concrete covers with different widths of crack in Group A were plotted in Figure 7, when the exposure duration $160 \mathrm{~d}$ was finished. As can be seen from Figure 7, the chloride content decreased as the depth increased from surface to $30 \mathrm{~mm}$, where the chloride content decreased rapidly as the depth increased from surface to $15 \mathrm{~mm}$, and the chloride content decreased slowly as the depth increased from $15 \mathrm{~mm}$ to $30 \mathrm{~mm}$. It can be seen from
Figure 7 that the chloride content increased as the crack widths increased and when the crack width was 120 microns, the chloride content was obviously larger.

The chloride contents at different depths of concrete cover with different crack widths in Groups A, B, C, and D are shown in Figures 8(a), 8(b), 8(c), and 8(d), respectively. Since the chloride content at depth $0 \sim 6 \mathrm{~mm}$ showed a large discreteness, the data at this depth was abandoned here.

As shown in Figures 8(a), 8(b), 8(c), and 8(d), the chloride content at the same depth increased as the crack width increased from 0 to 120 microns. As can be seen from Figure 8(a), the chloride content changed little when crack width was less than 90 microns, and the chloride content increased significantly when the crack width was larger than 90 microns. As can be seen from Figures 8(b), 8(c), and 8(d), with the wet-dry ratios of $1: 7,1: 11$, and $1: 15$, the chloride 


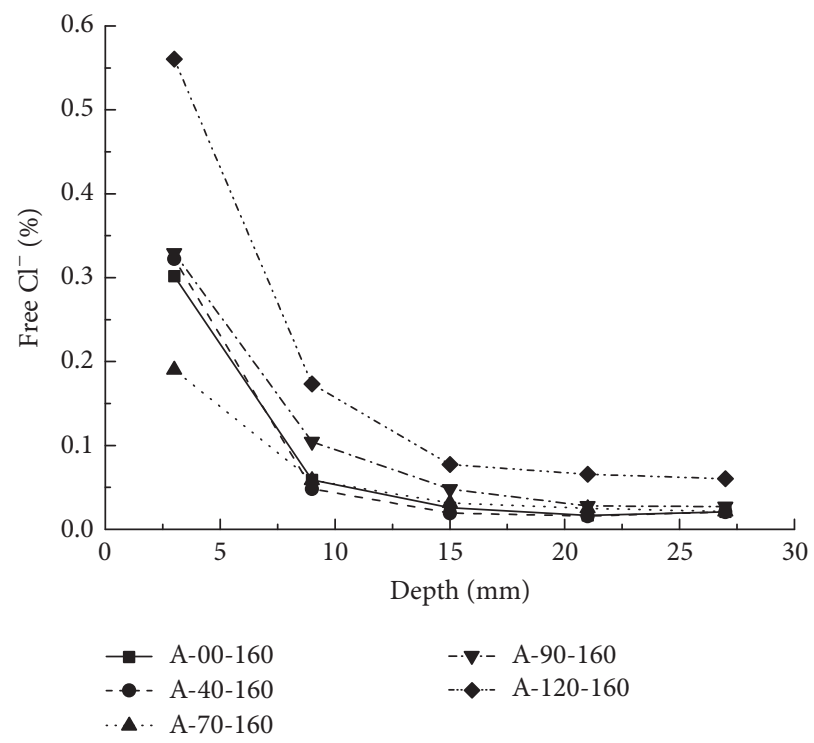

FIgURE 7: Chloride contents along the depth of concrete cover with different crack widths in Group A.
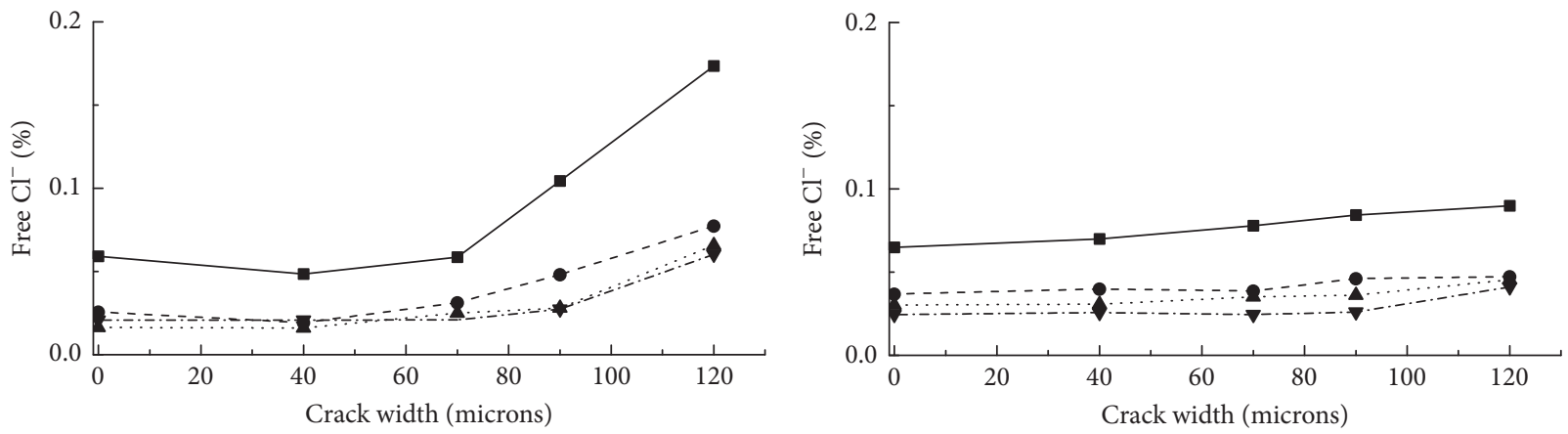

$\rightarrow$ Depth: $6-12 \mathrm{~mm}$

-.. Depth: $18-24 \mathrm{~mm}$

- Depth: $12-18 \mathrm{~mm}$

- Depth: $24-30 \mathrm{~mm}$

(a)

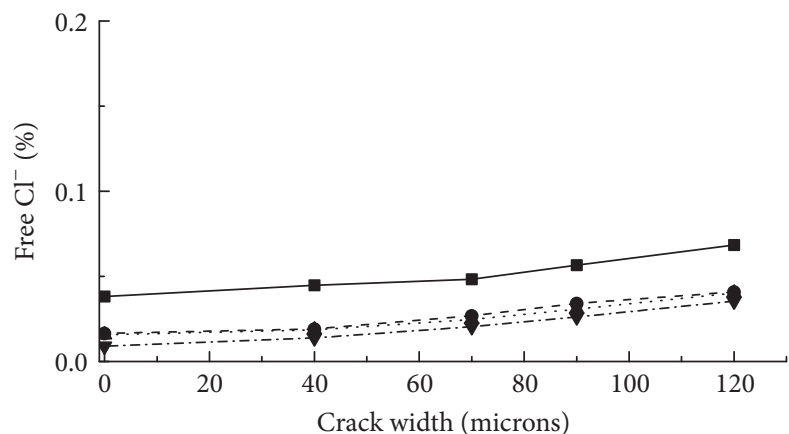

$\rightarrow$ Depth: 6-12 mm

- Depth: $12-18 \mathrm{~mm}$

A. Depth: $18-24 \mathrm{~mm}$

-- Depth: $24-30 \mathrm{~mm}$

(c)
- Depth: 6-12 mm … Depth: $18-24 \mathrm{~mm}$

(b)

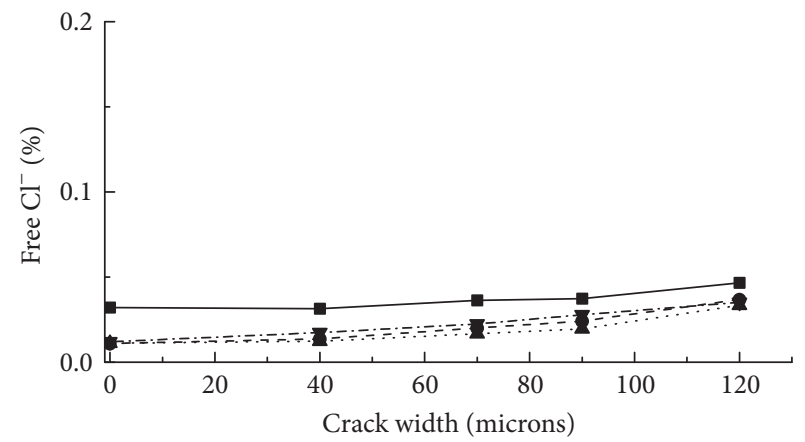

$\rightarrow$ Depth: 6-12 mm

(.) Depth: 18-24 mm

- - Depth: $12-18 \mathrm{~mm}$

- - - Depth: $24-30 \mathrm{~mm}$

(d)

FIGURE 8: Chloride content with different crack widths and different wet-dry ratios. (a) Group A (1:3); (b) Group B (1:7); (c) Group C (1:11); (d) Group D (1:15). 
TABLE 6: Chloride content on steel bar surface (\%) and its increment compared with uncracked concrete (\%).

\begin{tabular}{lcccccccc}
\hline $\begin{array}{l}\text { Crack width } \\
(\text { microns })\end{array}$ & $\begin{array}{c}\text { Chloride content } \\
\mathrm{A}(160 \mathrm{~d})\end{array}$ & $\begin{array}{c}\text { Incr. } \\
\mathrm{A}(160 \mathrm{~d})\end{array}$ & $\begin{array}{c}\text { Chloride content } \\
\mathrm{B}(160 \mathrm{~d})\end{array}$ & $\begin{array}{c}\text { Incr. } \\
\mathrm{B}(160 \mathrm{~d})\end{array}$ & $\begin{array}{c}\text { Chloride content } \\
\mathrm{C}(144 \mathrm{~d})\end{array}$ & $\begin{array}{c}\text { Incr. } \\
\mathrm{C}(144 \mathrm{~d})\end{array}$ & $\begin{array}{c}\text { Chloride content } \\
\mathrm{D}(160 \mathrm{~d})\end{array}$ & $\begin{array}{c}\text { Incr. } \\
\mathrm{D}(160 \mathrm{~d})\end{array}$ \\
\hline $\mathbf{0 0}$ & 0.0208 & 0.00 & $\mathbf{0 . 0 2 4 5}$ & 0.00 & 0.0090 & 0.00 & 0.0121 & 0.00 \\
$\mathbf{4 0}$ & 0.0217 & 4.33 & $\mathbf{0 . 0 2 5 7}$ & 4.90 & 0.0138 & 53.33 & 0.0174 & 43.80 \\
$\mathbf{7 0}$ & 0.0226 & 8.65 & $\mathbf{0 . 0 2 5 4}$ & 3.67 & 0.0204 & 126.67 & 0.0225 & 85.95 \\
$\mathbf{9 0}$ & $\mathbf{0 . 0 2 7 9}$ & 34.13 & 0.0260 & 6.12 & 0.0262 & 191.11 & 0.0270 & 123.14 \\
$\mathbf{1 2 0}$ & $\mathbf{0 . 0 6 0 4}$ & 190.38 & 0.0411 & 67.76 & 0.0354 & 293.33 & 0.0352 & 190.91 \\
\hline
\end{tabular}

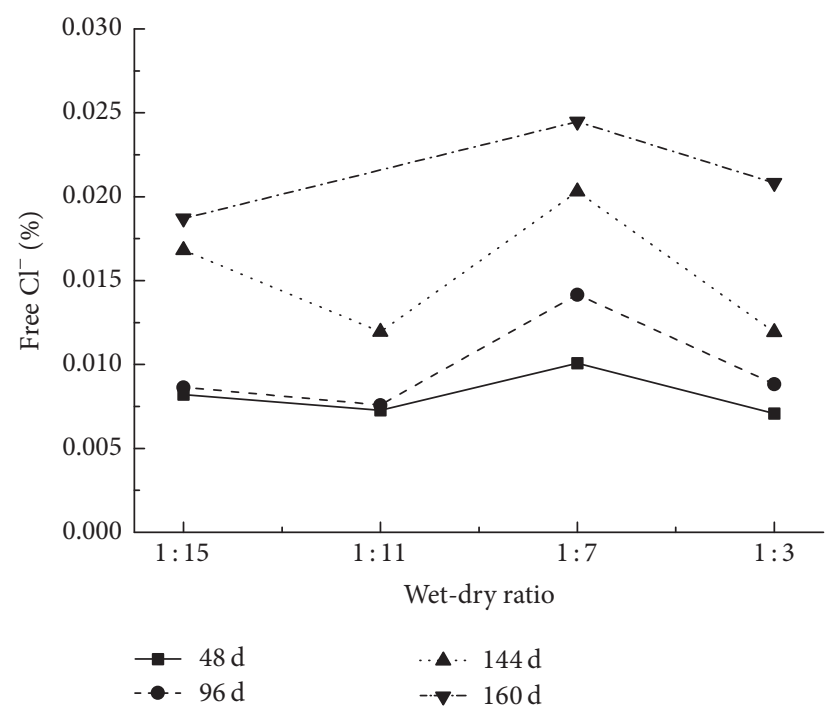

FIGURE 9: Chloride content on steel bar surface of uncracked concrete with different wet-dry ratios and different durations.

content changed little when crack width was equal to or less than 90 microns and the chloride content increased slightly when the crack width was 120 microns.

In conclusion, when wet-dry ratio was $1: 3$, the chloride content along the depth of concrete cover increased significantly as crack width was larger than 90 microns and when wet-dry ratios were $1: 7,1: 11$, and $1: 15$, chloride content increased slightly as crack width increased from 0 to 120 microns. A possible explanation was that the evaporation of pore solution influenced the concentration difference along the depth of concrete cover, which leads to different penetration rate of chloride ion during wetting process.

3.2.2. Effect of Wet-Dry Ratios on Chloride Content. The chloride content on steel bar surface of uncracked concrete with different wet-dry ratios (Groups A, B, C, and D) and different exposure durations are plotted in Figure 9. As shown in Figure 9, for the same duration, when wet-dry ratio increased from $1: 15$ to $1: 3$, the chloride content on steel bar surface changed and reached the largest value when the wetdry ratio was $1: 7$, and the chloride content on steel bar surface increased as the exposure duration increased from $48 \mathrm{~d}$ to $160 \mathrm{~d}$.
The chloride contents on steel bar surface and the increments of chloride content compared with uncracked concrete in the same group were listed in Table 6, where wet-dry ratios of four groups were A (1:3), B (1:7), C (1:11), and D (1:15), respectively. As shown in Table 6, for the same group, the chloride content on steel bar surface increased as the crack width increased. And the increment of chloride content also increased as the crack width increased, compared with the chloride content of uncracked RC beam specimens in the same group. When crack width was 120 microns, the chloride content on steel bar surface was the largest and the increment was $190.38 \%, 67.76 \%, 293.33 \%$, and $190.91 \%$ for Groups A, B, $\mathrm{C}$, and $\mathrm{D}$, respectively. When wet-dry ratio was $1: 3$ or $1: 7$, the increment of the chloride content on steel bar surface with crack width of 40 microns or 70 microns was smaller than $10 \%$, while the increment of the chloride content on steel bar surface increased sharply when crack width was greater than 90 microns. When wet-dry ratio was $1: 11$ or $1: 15$ and crack width was 40 microns, the increment of chloride content was $53.33 \%$ or $43.80 \%$, respectively, while the chloride content was relatively small. This indicated that as the wet-dry ratio decreased to $1: 11$ or $1: 15$, cracks had significant effect on the increment of the chloride content.

A possible explanation of the results in Figure 9 and Table 6 was that convection zone increased due to the extension of wet-dry cycles [4]. Based on the "inkbottle effect" and "hysteresis" $[15,16]$, the water evaporation rate in the drying process was obviously lagging behind the penetration rate of liquid in the wetting process. And when the drying duration was not enough for evaporation of the pore solution, diffusion played the major role and convection effect was not evident during the next wetting process [4], while the penetration rate would be accelerated because of wide concentration difference between the inside and outside solution [2]. As wet-dry ratio decreased from $1: 3$ to $1: 15$, the drying duration became longer and chloride penetration was accelerated, while the duration of concrete surface exposed to $\mathrm{NaCl}$ solution was shortened, which led to a decrease of the total chloride ion in concrete. So moderate drying duration was more conducive to chloride diffusivity.

The chloride contents on steel bar surface with different crack widths in different groups of wet-dry ratios were plotted in Figure 10, where the chloride content of exposure duration $96 \mathrm{~d}$ was shown in Figure 10(a) and that of exposure duration $160 \mathrm{~d}$ was shown in Figure 10(b). The ratios of chloride content in four groups and chloride content in reference group were listed in Table 7, where the wet-dry ratios of 


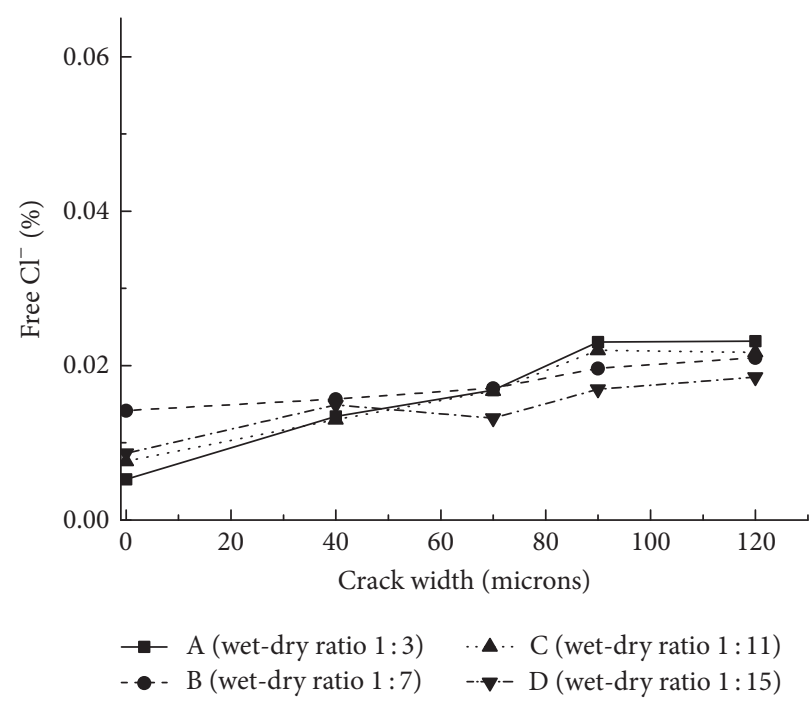

(a)

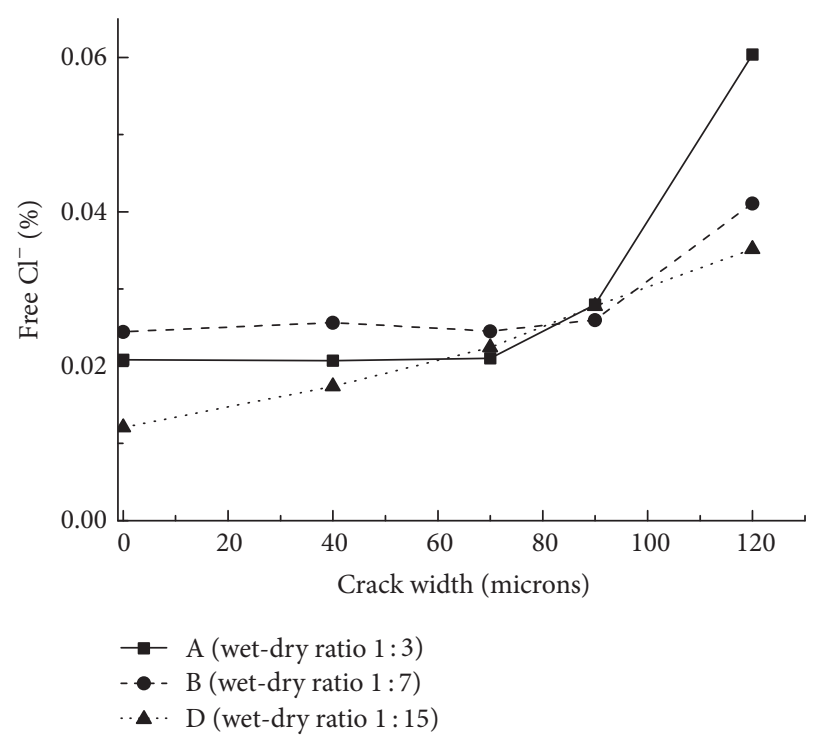

(b)

FIGURE 10: Chloride content on steel bar surface with different wet-dry ratios and different crack widths: (a) exposure duration $96 \mathrm{~d}$; (b) exposure duration $160 \mathrm{~d}$.

TABLE 7: Ratio of chloride content on steel bar surface of Groups A, $\mathrm{B}, \mathrm{C}$, and $\mathrm{D}$ and reference group.

\begin{tabular}{lcccc}
\hline Group & A $(160 \mathrm{~d})$ & B $(160 \mathrm{~d})$ & $\mathrm{C}(144 \mathrm{~d})$ & $\mathrm{D}(160 \mathrm{~d})$ \\
\hline 00 microns & 3.22 & $\mathbf{3 . 7 9}$ & 1.39 & 1.87 \\
40 microns & 3.36 & $\mathbf{3 . 9 8}$ & 2.14 & 2.69 \\
70 microns & 3.50 & $\mathbf{3 . 9 3}$ & 3.16 & 3.48 \\
90 microns & $\mathbf{4 . 3 2}$ & 4.02 & 4.06 & 4.18 \\
120 microns & $\mathbf{9 . 3 5}$ & 6.36 & 5.48 & 5.45 \\
\hline
\end{tabular}

four groups were $\mathrm{A}=1: 3, \mathrm{~B}=1: 7, \mathrm{C}=1: 11$, and $\mathrm{D}=1: 15$, respectively, and the duration of wet-dry cycles for Groups A, B, and D was $160 \mathrm{~d}$ and for Group C was $144 \mathrm{~d}$.

As can be seen from Figure 10 and Table 7, when crack width was less than 90 microns, chloride content of Group B (wet-dry ratio 1:7) was the largest of four groups. And when crack width was equal to or greater than 90 microns, chloride content of Group A (wet-dry ratio 1:3) was the largest.

A possible explanation was that when crack width was 90 or 120 microns, the wider crack was conducive to evaporation of pore solution and led to a wide concentration difference between the inside and outside solution, even the wet-dry ratio was 1:3 (Group A). And when crack widths were less than 90 microns, the wetting duration in Group B (wetdry ratio 1:7) was shorter than Group $A$, and the chloride diffusivity was improved due to less hydration of cement and less self-healing effect of crack, which indicated that moderate drying duration was more conducive to chloride diffusivity.

3.2.3. Effect of Exposure Duration on Chloride Content. The time dependency of chloride content on steel bar surface in four groups with wet-dry ratios of $1: 3,1: 7,1: 11$, and $1: 15$ were plotted in Figures 11(a), 11(b), 11(c), and 11(d), respectively. It can be seen from Figure 11(a), in Group A (wet-dry ratio $1: 3$ ), that the chloride content changed little when exposure duration was shorter than $96 \mathrm{~d}$ and the chloride content increased significantly when exposure duration increased from $96 \mathrm{~d}$ to $160 \mathrm{~d}$. It can be seen from Figures 11(b), 11(c), and 11(d), in the rest of the three groups, that the chloride content changed little when the exposure duration was less than $96 \mathrm{~d}$, and the chloride content increased significantly when crack width was larger than 90 microns and the exposure duration was larger than $96 \mathrm{~d}$.

In conclusion, chloride content on steel bar surface increased sharply when exposure duration was larger than $96 \mathrm{~d}$ and crack width was larger than 90 microns for all four groups.

\section{Apparent Chloride Diffusion Coefficient $\left(D_{\omega}\right)$ and Service Life Prediction}

4.1. Effect of Exposure Duration on Chloride Diffusion Coefficient. Based on Fick's second law and related research of chloride diffusion of concrete, surface chloride content $\left(C_{s}\right)$ and apparent chloride diffusion coefficient $\left(D_{\omega}\right)$ were obtained by regression analysis using (1) as to result into the best fit curve [17]. Because (1) only considered the effect of diffusion, the convection zone was removed in the fitting process.

$$
C(x, t)=C_{s}\left[1-\operatorname{erf}\left(\frac{x}{2 \sqrt{D_{\omega} t}}\right)\right],
$$

where $C(x, t)$ is the chloride content of concrete at the depth $x$ and the exposure duration $t$. 

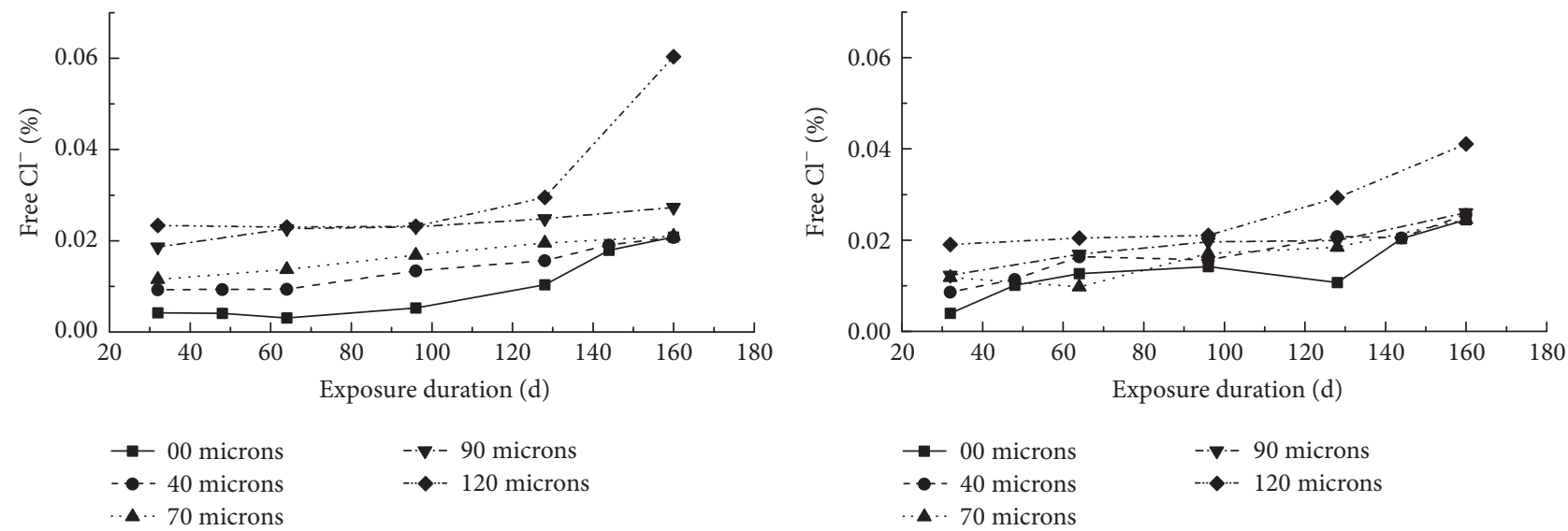

(a)

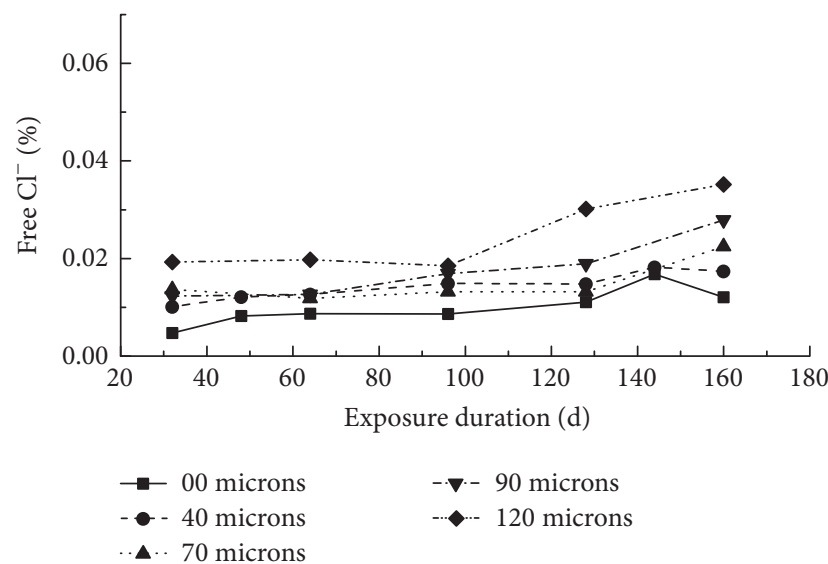

(c)

(d)

FIGURE 11: Chloride content on steel bar surface with different exposure durations and different crack widths. (a) Group A (1:3); (b) Group B (1:7); (c) Group C (1:11); (d) Group D (1:15).

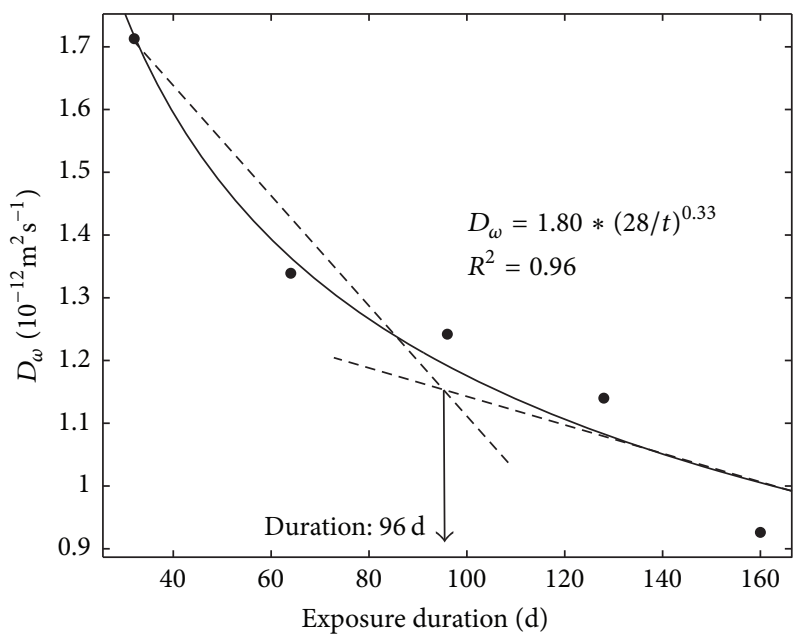

Figure 12: $D_{\omega}$ versus exposure duration.

The time-dependent change of $D_{\omega}$ in uncracked concrete of Group B is given in Figure 12. According to the study of
Thomas and Bamforth [18], the time dependency of $D_{\omega}$ can be described as follows [7]:

$$
D_{\omega}(t)=D_{28}\left(\frac{28}{t}\right)^{\alpha_{t}}
$$

where $D_{\omega}(t)$ is the apparent chloride diffusion coefficient $\left(10^{-12} \mathrm{~m}^{2} / \mathrm{s}\right) ; t$ is the exposure duration of wet-dry cycles (day); $D_{28}$ is the apparent chloride diffusion coefficient at age of $28 \mathrm{~d}\left(10^{-12} \mathrm{~m}^{2} / \mathrm{s}\right) ; \alpha_{t}$ is the time decay factor.

As can be seen from Figure 12, $D_{\omega}$ decreased from 1.72 $\times 10^{-12}$ to almost $1.01 \times 10^{-12} \mathrm{~m}^{2} / \mathrm{s}$ as exposure duration increased to $160 \mathrm{~d}$. In Figure 12, two time-dependent trends of $D_{\omega}$ were observed and they were represented by two dashed lines. The intersection of two dashed lines was $96 \mathrm{~d}$, which implied that exposure duration $96 \mathrm{~d}$ was a critical value. When exposure duration increased from $32 \mathrm{~d}$ to $96 \mathrm{~d}$, $D_{\omega}$ decreased sharply from $1.72 \times 10^{-12}$ to almost $1.20 \times$ $10^{-12} \mathrm{~m}^{2} / \mathrm{s}$. When exposure duration increased from $96 \mathrm{~d}$ to $160 \mathrm{~d}, D_{\omega}$ decreased slowly from almost $1.20 \times 10^{-12}$ to almost $1.01 \times 10^{-12} \mathrm{~m}^{2} / \mathrm{s}$. The relationship between $D_{\omega}$ and exposure duration was regressed and the result was given by solid line in Figure 12. The coefficient of determination $\left(R^{2}\right)$ was 0.96 , which indicated correlation was well. 
TABLE 8: $D_{28}$ and $\alpha_{\omega}$ of different crack widths.

\begin{tabular}{lcc}
\hline Crack width & $D_{28}\left(10^{-12} \mathrm{~m}^{2} / \mathrm{s}\right)$ & $\alpha_{\omega}$ \\
\hline 00 microns & 1.80 & 1.00 \\
40 microns & 1.83 & 1.02 \\
70 microns & 1.95 & 1.08 \\
90 microns & 2.83 & 1.57 \\
120 microns & 5.64 & 3.13 \\
\hline
\end{tabular}

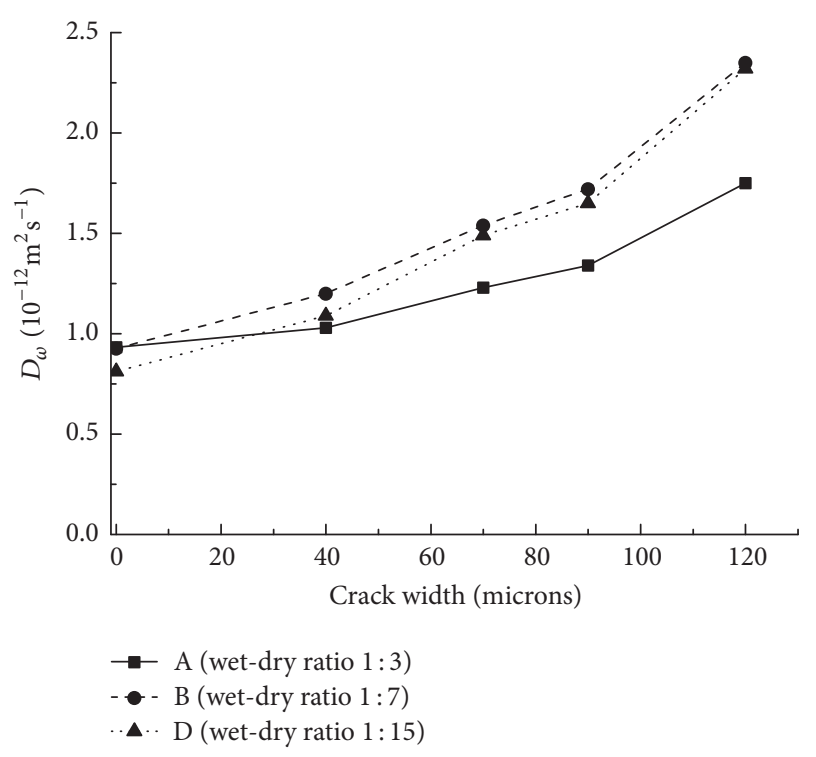

FIgURE 13: $D_{\omega}$ versus crack width $(160 \mathrm{~d})$.

4.2. Effect of Crack Widths and Wet-Dry Ratios on Chloride Diffusion Coefficient. After $160 \mathrm{~d}$ of wet-dry cycles, $D_{\omega}$ in Groups A, B, and D are plotted in Figure 13. As shown in Figure 13, $D_{\omega}$ increased as crack width increased and $D_{\omega}$ increased slowly as crack width increased from 0 to 90 microns and increased sharply as crack width increased from 90 to 120 microns. It implied that width of 90 microns was a critical value to consider the effect of crack width on chloride diffusion coefficient.

Besides, as shown in Figure 13, when crack width was 0 and 40 microns, wet-dry ratio had little influence on $D_{\omega}$; and $D_{\omega}$ achieved the largest values when wet-dry ratio was $1: 7$ for all crack widths. This means that moderate ratio of wetting and drying duration would be conductive to the chloride ingress; that is, wet-dry ratio $1: 7$ was the critical wet-dry ratio for lab accelerated test.

The crack factor $\alpha_{\omega}$ was introduced to consider the effect of initial crack. The apparent chloride diffusion coefficient of concrete at $28 \mathrm{~d}$ in Group B (wet-dry ratio 1:7) was obtained by (2) and the ratio of this apparent chloride diffusion coefficient between cracked concrete $\left(D_{c}\right)$ and uncracked concrete $\left(D_{0}\right)$ was listed in Table 8. Crack factor $\alpha_{\omega}$ was calculated by (3) and the result of $\alpha_{\omega}$ was given in Figure 14 and Table 8.

$$
\alpha_{\omega}=\frac{D_{c}}{D_{0}} .
$$

TABLE 9: $C_{s}$ and decrement.

\begin{tabular}{lccccc}
\hline Group & $\lambda$ & $\lambda_{t}$ & $R^{2}$ & $C_{s}(160 \mathrm{~d})$ & Decrement \\
\hline A (wet-dry 1:3) & $1.42 * 10^{-5}$ & 0.065 & 0.91 & 0.55 & 1 \\
B (wet-dry 1:7) & $1.29 * 10^{-5}$ & 0.065 & 0.92 & 0.50 & $9.1 \%$ \\
D (wet-dry 1:15) & $0.57 * 10^{-5}$ & 0.065 & 0.83 & 0.22 & $60.0 \%$ \\
\hline
\end{tabular}

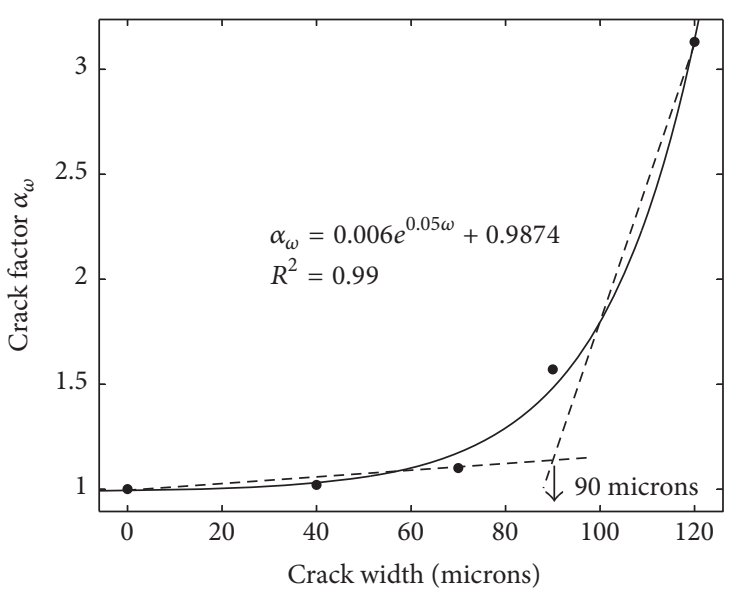

FIGURE 14: $\alpha_{\omega}$ versus crack width.

As can be seen from Figure 14, $\alpha_{\omega}$ increased from 1 to 3.13 as crack width increased to 120 microns. In Figure 14, two development trends of $\alpha_{\omega}$ were observed and they were represented by two dashed lines. The intersection of two dashed lines was 90 microns, which implied that crack width of 90 microns was a critical value. When crack width increased from 0 to 90 microns, $\alpha_{\omega}$ increased slowly from 1 to almost 1.53. When crack width increased from 90 to 120 microns, $\alpha_{\omega}$ increased sharply from almost 1.53 to 3.13 . The relationship between $\alpha_{\omega}$ and crack width was regressed and the result was given by solid line in Figure 14. The coefficient of determination $\left(R^{2}\right)$ was 0.99 , which indicated correlation was well.

4.3. Effect of Exposure Duration and Wet-Dry Ratios on $C_{s}$. As mentioned above, (1) was used to obtain the surface chloride content $\left(C_{s}\right)$ by curve fitting. In this paper, the specimen surface was under unsaturated state because of seawater wet-dry cycles and subsequently $C_{s}$ increased as exposure duration increased. To describe the time dependency of the surface chloride content $\left(C_{s}\right),(4)$ [5] was obtained by regression based on the results of the surface chloride content $\left(C_{s}\right)$ from Groups A, B, and D.

$$
C_{s}=\lambda \cdot e^{\left(\lambda_{t} \cdot t\right)}
$$

where $\lambda$ is an environmental parameter; $\lambda_{t}$ is a timedependent parameter; $t$ is the exposure duration of wet-dry cycles (day).

Table 9 gives the value of the surface chloride content $\left(C_{s}\right)$ from (1) and the regression results of $\lambda, \lambda_{t}$, and its determination coefficient $\left(R^{2}\right)$ from Groups $\mathrm{A}, \mathrm{B}$, and D as well as the decrement of $C_{s}$ compared with $C_{s}$ of Group 
A. As can be seen from Table 9, compared with $C_{s}$ of Group $\mathrm{A}, C_{s}$ in Groups B and D decreased by $9.1 \%$ and $60.0 \%$, respectively. It was indicated that $C_{s}$ was significantly affected by the environment; that is, with the decrease of the proportion of wetting time, surface chloride content significantly decreased.

\subsection{Life Prediction considering Cracks, Wet-Dry Ratios, and Exposure Durations}

4.4.1. Model of Life Prediction. Recently, in order to calculate the chloride profile resulting from ingress of penetrating chlorides, many researches have adopted model of chloride transmission in concrete proposed by Collepardi et al. [19] according to Fick's second law of one-dimensional unsteady flowing [20], and its mathematical expression is

$$
\frac{\partial C(x, t)}{\partial t}=D \frac{\partial^{2} C(x, t)}{\partial x^{2}}
$$

where $x$ is the depth; $t$ is exposure duration; $C(x, t)$ is the chloride content of concrete at the depth $x$ and exposure duration $t ; D$ is the apparent chloride diffusion coefficient at duration $t$.

Collepardi et al. [19] assumed the initial and boundary conditions $\left(C(x, t=0)=0\right.$ and $\left.C(x=0, t)=C_{s}\right)$ and simplified (5) into (6) through the function (erf).

$$
C(x, t)=C_{s}-\left(C_{s}-C_{i}\right) \cdot \operatorname{erf}\left(\frac{x}{2 \sqrt{D_{w} \cdot t}}\right),
$$

where $C_{s}$ is surface chloride content and $C_{i}$ is initial chloride content.

In the theory of life prediction of chloride diffusion, the end point of the durability life of structures is that the chloride content on steel surface reaches critical value $\left(C_{\mathrm{cr}}\right)$ [21]. Thus, in this study, it is assumed that time to corrosion initiation was reached when the chloride content on the steel surface has reached the critical chloride content $C_{c r}$. With America ACI222 [22] and Europe BS-EN206 [23] as reference, $C_{c r}=$ $0.063 \%\left(\mathrm{~g} / \mathrm{cm}^{3}\right)$; that is, $0.2 \%$ of cement weight was adopted in this paper.

As it was concluded in Section 4.1, the chloride diffusion coefficient $\left(D_{\omega}\right)$ decreased as exposure duration increased in service life. Stanish and Thomas [24] used (7) to describe the time-dependent change of chloride diffusion coefficient,

$$
D_{t}=D_{\text {ref }}\left(\frac{t_{\text {ref }}}{t}\right)^{m}
$$

where $D_{t}$ is chloride diffusion coefficient at time $t, D_{\text {ref }}$ is the chloride diffusion coefficient at reference time $t_{\text {ref }}\left(t_{\text {ref }}=\right.$ $28 \mathrm{~d}$ ), and $m$ is the so-called ageing factor.

According to study of Stanish and Thomas [24], the relationship between $D_{t}$ and $t$ can be expressed as follows:

$$
D_{t}= \begin{cases}D_{\text {ref }}\left(\frac{t_{\text {ref }}}{t}\right)^{m} & t \leq t_{R} \\ D_{\text {ref }}\left(\frac{t_{\text {ref }}}{t_{R}}\right)^{m}=D_{t_{R}} & t>t_{R}\end{cases}
$$

where $t_{R}$ is the time after which the diffusion coefficient is assumed to remain constant and $t_{R}$ is generally assumed to be 30 years [12].

Tang and Gulikers [25] substitute (8) into (9) to get $T$. Consequently, $T$ can be expressed by (10),

$$
T=\int_{t_{1}}^{t_{2}} D_{t} d t
$$

$T$

$$
= \begin{cases}\frac{D_{\mathrm{ref}}\left(t_{\mathrm{ref}}\right)^{m}}{(1-m)}\left(t_{2}^{1-m}-t_{1}^{1-m}\right) & t_{2} \leq t_{R} \\ D_{\mathrm{ref}}\left[\frac{\left(t_{\mathrm{ref}}\right)^{m}\left(t_{R}^{1-m}-t_{1}^{1-m}\right)}{(1-m)}+\left(\frac{t_{\mathrm{ref}}}{t_{R}}\right)^{m}\left(t_{2}-t_{R}\right)\right] & t_{2}>t_{R},\end{cases}
$$

where $t_{1}$ is the start of exposure period and $t_{2}$ is the end of exposure period.

In this paper, crack factor $\left(\alpha_{\omega}\right)$ was introduced to consider the effect of cracks and (3) was used to take the place of $D_{t}$ in (9), referring to Section 4.2. And time decay factor $\left(\alpha_{t}\right)$ was introduced to take the place of $m$, referring to Section 4.1. So $T$ can be calculated by (11) which are derived from (10). Based on $C_{s}$ and $D_{\text {ref }}$ of each sample, substituting the critical chloride content $C_{\mathrm{cr}}=0.063 \%$, concrete cover $x=30 \mathrm{~mm}, t_{1}$ $=t_{\text {ref }}=28 \mathrm{~d}, t_{R}=30$ year, and each $C_{i}, \alpha_{\omega}$, and $\alpha_{t}$ into (12), the magnitude of $t_{2}$ could be calculated as calculated service life.

$$
\begin{aligned}
T & = \begin{cases}\alpha_{\omega} \frac{D_{\text {ref }}\left(t_{\text {ref }}\right)^{\alpha_{t}}}{\left(1-\alpha_{t}\right)}\left(t_{2}^{1-\alpha_{t}}-t_{1}^{1-\alpha_{t}}\right) & t_{2} \leq t_{R} \\
\alpha_{\omega} D_{\text {ref }}\left[\frac{\left(t_{\text {ref }}\right)^{\alpha_{t}}\left(t_{R}^{1-\alpha_{t}}-t_{1}^{1-\alpha_{t}}\right)}{\left(1-\alpha_{t}\right)}+\left(\frac{t_{\text {ref }}}{t_{R}}\right)^{\alpha_{t}}\left(t_{2}-t_{R}\right)\right] & t_{2}>t_{R}\end{cases} \\
C_{\mathrm{cr}}=C_{s}-\left(C_{s}-C_{i}\right) \cdot \operatorname{erf}\left(\frac{x}{2 \sqrt{T}}\right) . &
\end{aligned}
$$

4.4.2. Prediction of Residual Service Life. Figure 15 shows the residual service life of RC beam specimens in Groups A,
B, and D. As can be seen from Figure 15, as crack width increased to 120 microns, the residual service life of RC beam 


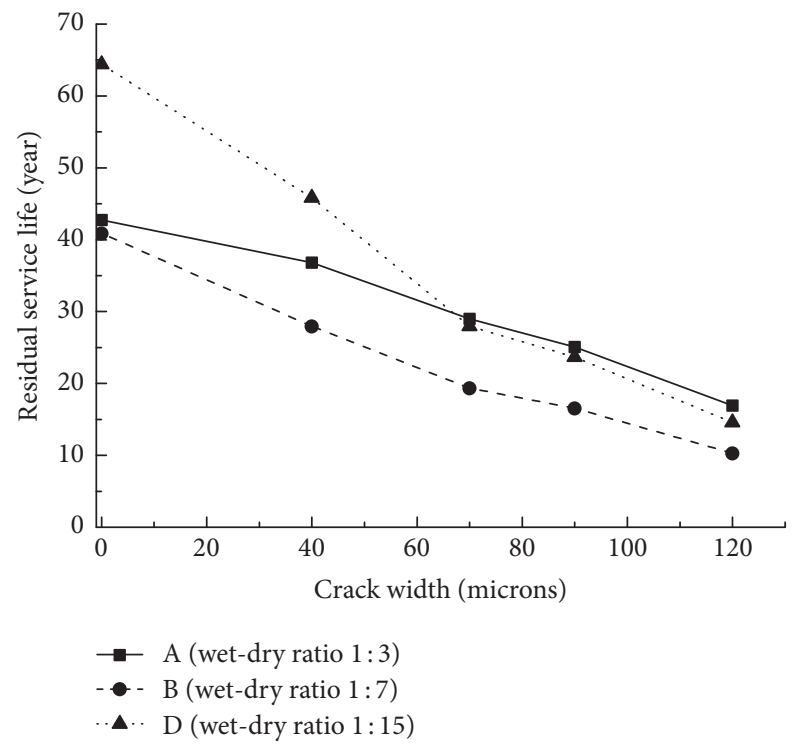

FIGURE 15: Residual service life of RC beams with the increase of crack widths.

specimens decreased from 43 years to 17 years in Group A (wet-dry ratio 1:3), 41 years to 10 years in Group B (wetdry ratio $1: 7$ ), and 64 years to 15 years in Group D (wetdry ratio $1: 15$ ), respectively. As mentioned above, chloride diffusivity of Group B (wet-dry ratio 1:7) was accelerated most and subsequently Group B (wet-dry ratio 1:7) showed the shortest residual service life, compared with Group A (wet-dry ratio 1:3) and Group D (wet-dry ratio 1:15).

\section{Conclusion}

This study investigated the combined effects of crack width, wet-dry ratio, and exposure duration of wet-dry cycles on chloride ions diffusion of RC beams to stimulate working conditions of RC structures. The chloride diffusion model was obtained based on the experiments, which considered crack width, wet-dry ratio, and exposure duration. The life prediction model of RC structures and critical value of chloride ion content were also concluded. Conclusions specifically are as follows:

(1) The chloride content along the depth of concrete cover increased significantly when crack width was larger than 90 microns and wet-dry ratio was $1: 3$, and the chloride content increased slightly as crack width increased from 0 to 120 microns when wet-dry ratios were $1: 7,1: 11$, and $1: 15$, respectively.

(2) When crack width was less than 90 microns and wetdry ratio was $1: 7$, the chloride content on steel bar surface was the largest of four wet-dry ratios $(1: 3,1: 7$, $1: 11$, and $1: 15)$. And when crack width was equal to or greater than 90 microns and wet-dry ratio was $1: 3$, the chloride content on steel bar surface was the largest.

(3) Based on the testing results of chloride content on steel bar surface and the analysis results of chloride diffusion coefficient, the suitable ratio of wetting and drying duration was $1: 7$, which was conductive to the chloride ingress for the cracked RC structures of working conditions.

(4) The chloride diffusion model and prediction model of residual service life of RC beams were suggested, taking the combined effects of crack width and exposure duration into consideration. The predicted residual service life decreased with the increase of crack width and the residual service lives of RC structures predicted here were corresponding well with the experimental results.

\section{Conflicts of Interest}

The authors declare that there are no conflicts of interest regarding the publication of this paper.

\section{Acknowledgments}

This work was financially supported by the National Natural Science Foundation of China (Grant no. 51678021) and the Open Project of State Key Laboratory of Subtropical Building Science, South China University of Technology (2016ZA03).

\section{References}

[1] B. Diao, Y. Sun, S. Cheng, and Y. Ye, "Effects of mixed corrosion, freeze-thaw cycles, and persistent loads on behavior of reinforced concrete beams," Journal of Cold Regions Engineering, vol. 25, no. 1, pp. 37-52, 2010.

[2] K. Hong and R. D. Hooton, "Effects of cyclic chloride exposure on penetration of concrete cover," Cement and Concrete Research, vol. 29, no. 9, pp. 1379-1386, 1999.

[3] C. Li and K. Li, "Chloride ion transport in cover concrete under drying-wetting cycles: theory, experiment and modeling," Journal of the Chinese Ceramic Society, no. 4, pp. 581-589, 2010 (Chinese).

[4] X. Gang, L. Yun-Pan, S. Yi-Biao, and X. Ke, "Chloride ion transport mechanism in concrete due to wetting and drying cycles," Structural Concrete, vol. 16, no. 2, pp. 289-296, 2015.

[5] W. Jin, Theory and Design Method of Durability of Concrete Structures in Chloride Environment, The Science Publishing Company, Beijing, China, 2011, (Chinese).

[6] P. S. Mangat and B. T. Molloy, "Prediction of long term chloride concentration in concrete," Materials and Structures, vol. 27, no. 6, pp. 338-346, 1994.

[7] M. K. Moradllo, M. Shekarchi, and M. Hoseini, "Timedependent performance of concrete surface coatings in tidal zone of marine environment," Construction and Building Materials, vol. 30, pp. 198-205, 2012.

[8] M. Şahmaran, "Effect of flexure induced transverse crack and self-healing on chloride diffusivity of reinforced mortar," Journal of Materials Science, vol. 42, no. 22, pp. 9131-9136, 2007.

[9] P. P. Win, M. Watanabe, and A. Machida, "Penetration profile of chloride ion in cracked reinforced concrete," Cement and Concrete Research, vol. 34, no. 7, pp. 1073-1079, 2004.

[10] Y. Lei, Y. Ye, B. Shen et al., "Effect of crack widths on durability of RC columns under seawater wet-dry cycles," Concrete, no. 5, pp. 18-22, 2015. 
[11] C. Q. Li, "Initiation of chloride-induced reinforcement corrosion in concrete structural members-experimentation," Structural Journal, vol. 98, no. 4, pp. 502-510, 2001.

[12] B. Shen, Y. Ye, B. Diao, and X. Zheng, "Mechanical performance and chloride diffusivity of cracked Rc specimens exposed to freeze-thaw cycles and intermittent immersion in seawater," Advances in Materials Science and Engineering, vol. 2016, Article ID 5973467, 10 pages, 2016.

[13] JTJ 270-98, “Testing code of concrete for port and waterwog engineering," Tech. Rep., China Communications Press, Beijing, China, 1998, (Chinese).

[14] Z. Liu, B. Diao, and X. Zheng, "Effects of seawater corrosion and freeze-thaw cycles on mechanical properties of fatigue damaged reinforced concrete beams," Advances in Materials Science and Engineering, vol. 2015, Article ID 536487, 15 pages, 2015.

[15] R. P. Chaube, T. Shimomura, and K. Maekawa, "Multiphase water movement in concrete as a multi-component system," in Proceeding of the 5th RILEM International Symposium on Creep and Shrinkage in Concrete, pp. 139-144, E \& FN, Barcelona, Spain, 1993.

[16] W. Jin, Y. Zhang, and Z. Lu, "Mechanism and mathematic modeling of chloride permeation in concrete under unsaturated state," Journal of the Chinese Ceramic Society, vol. 36, no. 10, pp. 1362-1369, 2008.

[17] E. P. Nielsen and M. R. Geiker, "Chloride diffusion in partially saturated cementitious material," Cement and Concrete Research, vol. 33, no. 1, pp. 133-138, 2003.

[18] M. D. A. Thomas and P. B. Bamforth, "Modelling chloride diffusion in concrete effect of fly ash and slag," Cement and Concrete Research, vol. 29, no. 4, pp. 487-495, 1999.

[19] M. Collepardi, A. Marcialis, and R. Turriziani, "Penetration of chloride ions into cement pastes and concretes," Journal of the American Ceramic Society, vol. 55, no. 10, pp. 534-535, 1972.

[20] M. Jiang, H. Lu, X. Kou et al., "Diffusion model study of chloride ion in concrete structure under chlorine salt corrosion environment," Concrete, no. 5, pp. 46-49, 2013 (Chinese).

[21] S. J. Kwon, U. J. Na, S. S. Park, and S. H. Jung, "Service life prediction of concrete wharves with early-aged crack: probabilistic approach for chloride diffusion," Structural Safety, vol. 31, no. 1, pp. 75-83, 2009.

[22] B. B. Hope and C. K. Nmai, Protection of Metals in Concrete against Corrosion, vol. 222, American Concrete Institute Committe, 2001.

[23] EN T S. 206-1, Concrete-Part 1: Specification, Performance, Production and Conformity, Turkish Standards Institution, Ankara, Turkey, 2002.

[24] K. Stanish and M. Thomas, "The use of bulk diffusion tests to establish time-dependent concrete chloride diffusion coefficients," Cement and Concrete Research, vol. 33, no. 1, pp. 55-62, 2003.

[25] L. P. Tang and J. Gulikers, "On the mathematics of timedependent apparent chloride diffusion coefficient in concrete," Cement and Concrete Research, vol. 37, no. 4, pp. 589-595, 2007. 

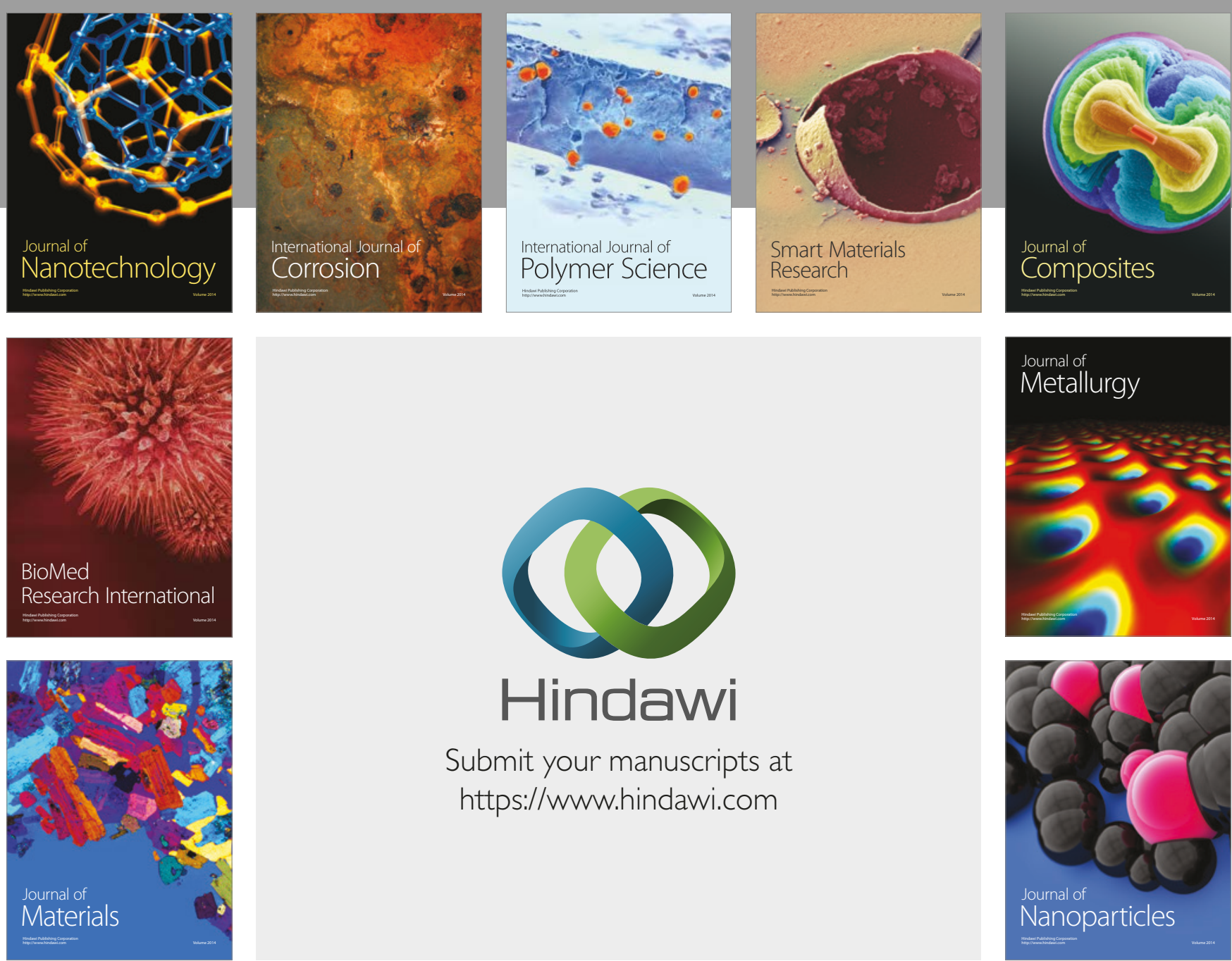

\section{Hindawi}

Submit your manuscripts at

https://www.hindawi.com
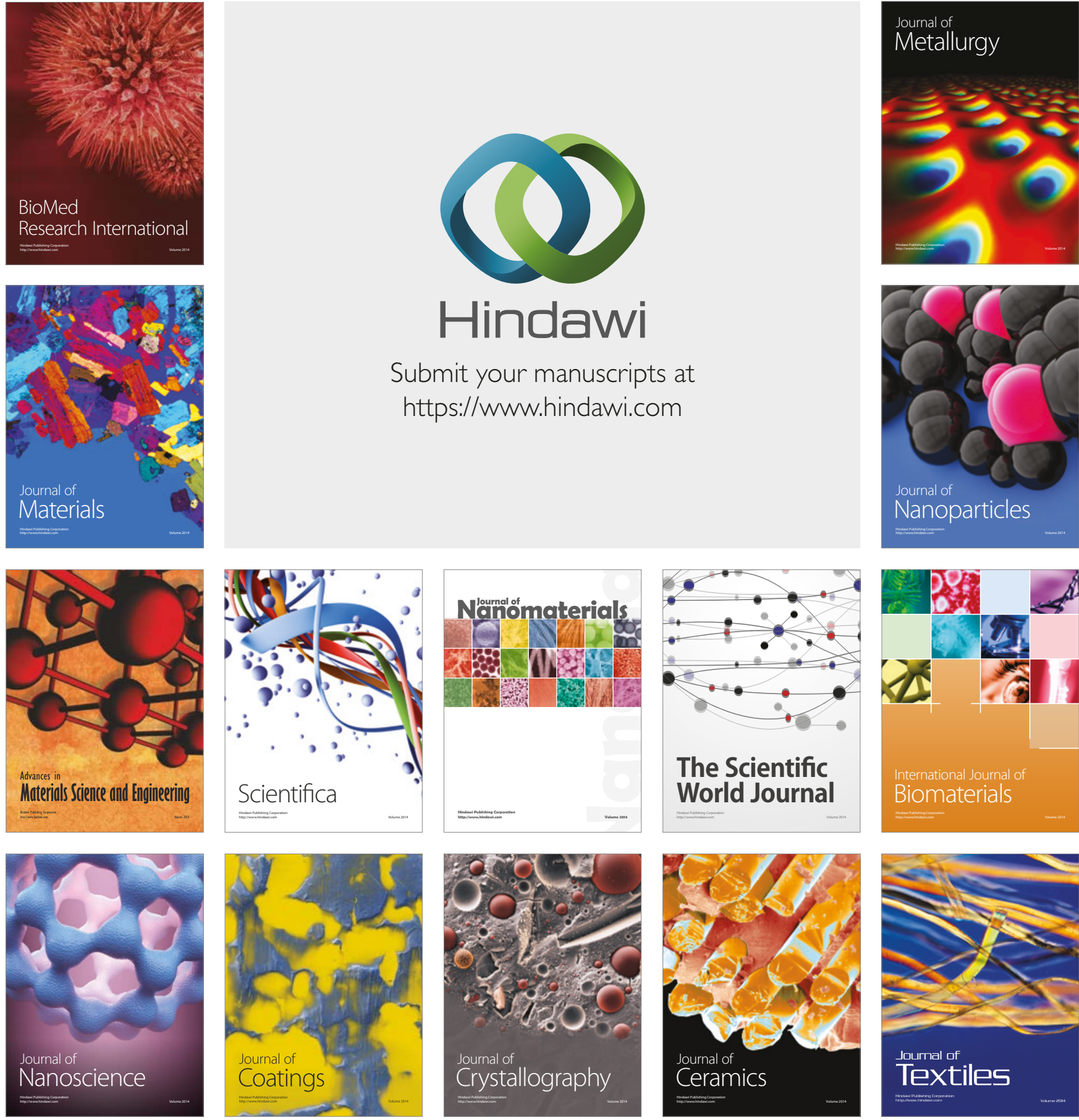

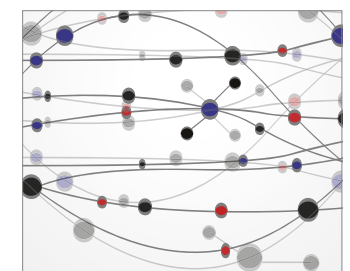

The Scientific World Journal
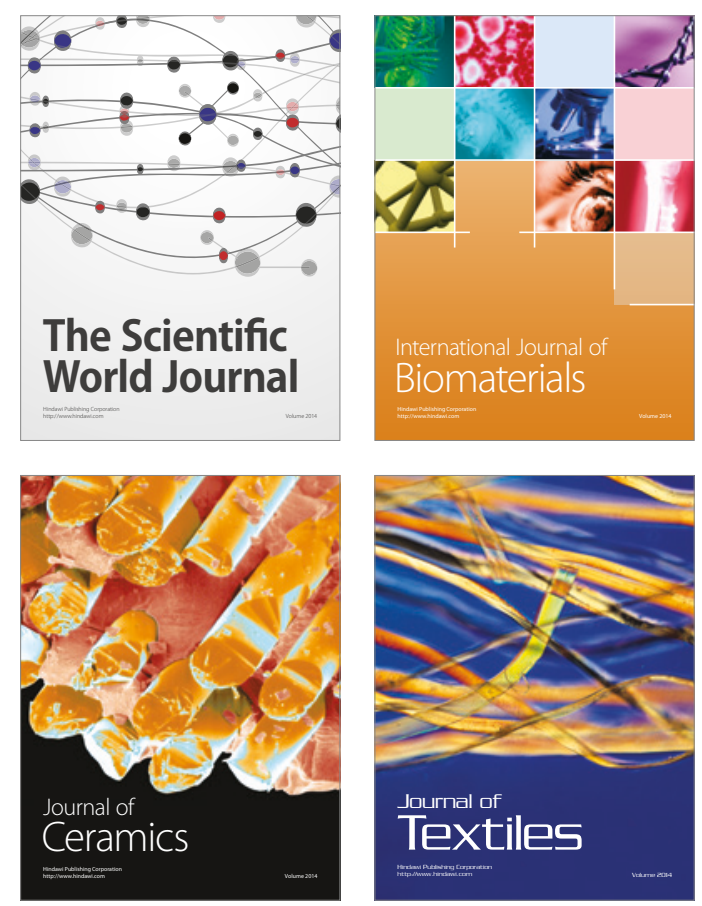